\title{
Sensory Systems of Primates
}




\section{ADVANCES IN PRIMATOLOGY}

Series Editors:

W. PATRICK LUCKETT

Creighton University School of Medicine

Omaha, Nebraska

CHARLES R. NOBACK

Columbia University

New York, New York

Editorial Board:

JOHN F. EISENBERG

Smithsonian Institution

Washington, D.C.

MORRIS GOODMAN

Wayne State University School of Medicine

Detroit, Michigan
F.A. JENKINS, Jr.

Harvard University

Cambridge, Massachusetts

FREDERICK S. SZALAY

Hunter College

New York, New York

\section{THE PRIMATE BRAIN}

Edited by Charles R. Noback and William Montagna

MOLECULAR ANTHROPOLOGY: Genes and Proteins

in the Evolutionary Ascent of the Primates

Edited by Morris Goodman and Richard E. Tashian

SENSORY SYSTEMS OF PRIMATES

Edited by Charles R. Noback

A Continuation Order Plan is available for this series. A continuation order will bring delivery of each new volume immediately upon publication. Volumes are billed only upon actual shipment. For further information please contact the publisher. 


\section{Sensory Systems of Primates}

Edited by

Charles R. Noback

Department of Anatomy

Columbia University

New York, New York 


\section{Library of Congress Cataloging in Publication Data}

Main entry under title:

Sensory systems of primates.

(Advances in primatology)

Includes bibliographies and index.

1. Nervous system-Mammals. 2. Primates. I. Noback, Charles Robert, 1916III. Series.

\section{(C) 1978 Plenum Press, New York}

Softcover reprint of the hardcover 1st edition 1978

A Division of Plenum Publishing Corporation 227 West 17th Street, New York, N.Y. 10011

\section{All rights reserved}

No part of this book may be reproduced, stored in a retrieval system, or transmitted, in any form or by any means, electronic, mechanical, photocopying, microfilming, recording, or otherwise, without written permission from the Publisher 


\section{Contributors}

John R. Cotтer, Department of Anatomical Sciences, State University of New York, Buffalo, New York

Leonard M. Eisenman, Department of Anatomy, Thomas Jefferson University, Philadelphia, Pennsylvania

Gisela Epple, Monell Chemical Senses Center, University of Pennsylvania, Philadelphia, Pennsylvania

John K. Harting, Department of Anatomy, University of Wisconsin, Madison, Wisconsin

Ralph L. Holloway, Department of Anthropology, Columbia University, New York, New York

Jon H. KaAs, Department of Psychology, Vanderbilt University, Nashville, Tennessee

Shyam M. Khanna, Department of Otolaryngology, College of Physicians and Surgeons, Columbia University, New York, New York

David Moulton, Monell Chemical Senses Center, University of

Pennsylvania, Philadelphia, Pennsylvania

Roberta Pierson Pentney, Department of Anatomical Sciences, State University of New York, Buffalo, New York

Norman L. Strominger, Department of Anatomy, Albany Medical

College of Union University, Albany, New York

Juergen Tonndorf, Department of Otolaryngology, College of Physicians and Surgeons, Columbia University, New York, New York Joseph T. Weber, Department of Anatomy, University of Wisconsin, Madison, Wisconsin 


\section{Preface}

Primates are avid explorers that utilize a variety of sensory clues from the environment. The special senses of olfaction, audition, and particularly vision are thus of paramount significance in the evolution and adaptive radiation of the primates. It was with this in mind that this volume was planned to present some recent research advances.

The chapter on olfactory communication among primates affords new insights concerning a sense which, though primatologists have generally relegated it to a minor role, is of considerable significance in the primates. The chapters on the auditory system are organized to stress three aspects: the receptive organ, the neural pathways, and the role of audition in primate communication. The visual system, the dominant special sense of primates, is analyzed with respect to two regions of the brain, namely, the organization of the superior colliculus and the visual cortex. Finally, the chapter on endocasts in the study of primate brain evolution will alert neurobiologists to the relevant information that can be unearthed from fossils embedded in the terrane.

I wish to thank the publishers, and especially Miss Phyllis Straw and Mr. Seymour Weingarten, for their support, patience, guidance, and professional assistance.

Charles R. Noback 


\section{Contents}

1. Structural Organization and Communicatory

Functions of Olfaction in Nonhuman

Primates 1

Gisela Epple and David Moulton

I. Introduction 1

II. Structural Organization 3

A. The Nasal Cavity and the Extent of Olfactory Surface 4

B. Olfactory Epithelium 4

C. Vomeronasal (Jacobson's) Organ and Epithelium, and the Accessory Olfactory Bulb 6

D. Olfactory Bulb 7

E. Secondary and Higher Projections of the Olfactory Bulb 8

III. Communicatory Functions of Olfactory Signals 10
A. Species Identity 11
B. Sexual Identity 11
C. Identification of Reproductive Condition
D. Individual Identity 15
E. Identification of Emotional and Social Condition 17

13

IV. References 18 


\section{Physical and Physiological Principles Controlling Auditory Sensitivity in Primates 23}

Shyam M. Khanna and Juergen Tonndorf

I. Introduction 23

II. The Ear as an Early Warning Device 31

III. Sensitivity of Detection 33
A. Minimization of Transmission Losses
B. Increase in Energy Collection 34
C. Sensitivity of Biological Mechanodetectors

IV. Directional Reception of Sound 38

A. Causes of Interaural Intensity Differences 39

B. Causes of Interaural Time Differences 40

C. Detection of Sound in the Presence of Noise 43

V. Brownian Noise 43

VI. Improvement in Sensitivity of Detection by Reduction of Noise 44

VII. The Effect of Narrow-Band Filters on Brownian Noise 44

VIII. Detection of Signals 46

IX. Multiple Sources of Noise 48

X. Concluding Remarks 49

XI. References 51

3. The Anatomical Organization of the Primate Auditory Pathways 53

Norman L. Strominger

I. Introduction 53

II. Morphological Aspects of the Auditory Pathway 54

A. Cochlear Nuclei 54

B. Superior Olivary Complex 61

C. Ventral and Dorsal Nuclei of the Lateral Lemniscus $\quad 65$ 
D. Inferior Colliculus 65

E. Cell Groups in Proximity to the Brachium of the Inferior Colliculus 68

F. Medial Geniculate Body 68

G. Auditory Cortex 69

III. The Course and Distribution of Primary Auditory Fibers 75

IV. Ascending Fiber Systems in the Central Nervous System 77

A. Fibers Arising from the Cochlear Nuclei 77

B. Efferent Connections of the Superior Olivary Complex 82

C. Projections of the Nuclei of the Lateral Lemniscus 83

D. Projections of the Inferior Colliculus 83

E. Efferent Connections of the Parabrachial and Interstitial Nuclei of the Brachium of the Inferior Colliculus 84

F. Geniculocortical Projections 84

V. Other Connections 86

VI. References 87

4. Vocal Communication in Primates 93 LeONARd M. Eisenman

I. Introduction 93

II. The Auditory Signal 94

A. Vocalization Repertoires 94

B. Neural Correlates of Vocalizations 96

C. Ontogeny of Vocalizations 98

III. Perception of Vocalizations 99

A. Auditory Sensitivity 99

B. Responses of Single Auditory Neurons 100

IV. Conclusions and Summary 104

V. References 105 
5. Structural and Functional Aspects of the Superior Colliculus in Primates 109

Roberta Pierson Pentney and John R. Cotter

I. Introduction 109

II. Anatomical Studies 110
A. Cytoarchitecture 110
B. Fiber Connections 114

III. Physiological Studies 119
A. Visual Field Representation
B. Unit Types in the Monkey Colliculus
120
C. Functional Considerations 123

IV. Behavioral Studies 124
A. Ablation Studies 124
B. Stimulation Studies

V. Summary and Conclusion
A. Anatomy 128
B. Physiology 128
C. Behavior 129

VI. References 130

6. Parallel Pathways Connecting the Primate Superior Colliculus with the Posterior Vermis: An Experimental Study Using Autoradiographic and Horseradish Peroxidase Tracing Methods 135

Joseph T. Weber and John K. Harting

I. Introduction 135

II. Materials and Methods 136

III. Results 137

A. The Tecto-Olivary Projection in the Rhesus Monkey 137

B. The Cerebellar Target of Subnucleus b 141

IV. Discussion 143

V. References 147 
7. The Organization of Visual Cortex in Primates 151

Jon H. KaAS

I. Introduction 151

II. The Visual Areas 153

A. The Traditional View of Visual Cortex 153

B. The Primary Visual Area 154

C. The Secondary Visual Area 156

D. Visual Areas beyond V II 158

III. Connections 164

A. Receiving and Projecting Neurons 165

B. Ipsilateral Connections 167

C. Callosal Connections 171

IV. The Significance of Multiple Representations
A. Evolution 173
B. Development 174
C. Functions 175

V. References 176

8. The Relevance of Endocasts for Studying Primate Brain Evolution 181

Ralph L. HollowaY

I. Introduction 181

II. Possible Lines of Evidence for Brain Evolution 182

III. Qualitative and Quantitative Descriptions 187

IV. Toward Fuller Morphometric Analyses 189
A. Study $1 \quad 189$
B. Study 2192
V. Addendum 195

VI. References 198

Index $\quad 201$ 